\title{
The Parametric Variations of English and Kanuri Noun Phrases: A Minimalist Approach
}

\author{
Correspondence: $\quad$ Baba Kura Alkali Gazali $\quad \mathrm{PhD}$ in English Linguistics, Department of Languages and Linguistics, University \\ <gazali1974@yahoo.co.uk> of Maiduguri, Nigeria
}

\begin{abstract}
This paper examines the parametric variations of English and Kanuri noun phrases (NPs) within the theoretical framework of Principles and Parameters (P\&P), and the study adopts Chomsky's (1995) Minimalist Approach (MA). In conducting the research, the researcher uses his native intuition to collect the data for this study. The secondary sources of data involve the use of three competent native speakers to validate the data. The outcome of the study reveals that there are differences and similarities between the two languages which are genetically different -Kanuri Nilo is a Saharan language while English is an Endo European language. The differences are: Kanuri is a head final language while English is head initial language. On the complement phrases, the two languages share dissimilarities -quantifiers and adjectives occur post head in Kanuri while the quantifiers and adjectives occur pre-head in English. Finally, the two languages share similarities in terms of noun plural formation morphologically suffixed to post head nouns and definiteness and agreement features [-Def] [+PL Num].
\end{abstract}

Keywords: Universal Grammar, parametric, variation, minimalist, noun phrase, complements

\section{Introduction}

This paper discusses the parametric variations between English and Kanuri languages. It covers the following settings: whether any particular language has an overt head constituent or not, whether the head of any phrase positions after or before the complement word (i.e., head-last or head-first). This principle constitutes the theoretical basis for this paper. The contrastive setting parameters between English and Kanuri languages are the purpose of our study in this paper. A phrase is described traditionally as "a label applied to any string of words which someone wants to consider" (Trask, 1993, p. 208). Another description advances by Radford (2004, p. 469) "as a term which is used to denote an expression larger than a word". However, phrase structure is a type of hierarchical structure which, in most theories of grammar is posited for most or all sentences in most or all languages. Radford (2004) sees phrase structure in a simpler way, "merging two words together" (Radford, 2004, p. 66). According to Chomsky (1995), the structure of a sentence is established by combining the words in pairs, one being the complement of the other i.e., this operation of combining the words together to form larger units out of those already constructed is called 'merging'. Merging determines the pairs of lexical items; having a complement of the other. Radford (2004) further observes thus “.... In all these descriptions, the one to which the phrase is referred or belongs is called the 'head' (H) of the phrase since the head of the phrase determines the grammatical properties of the complement and the other which completes the head is the 'complement' of the phrase" (p. 72). Radford (2004) provides the tree structure of phrase structure in the diagram below.

Figure 1. Phrase Structure

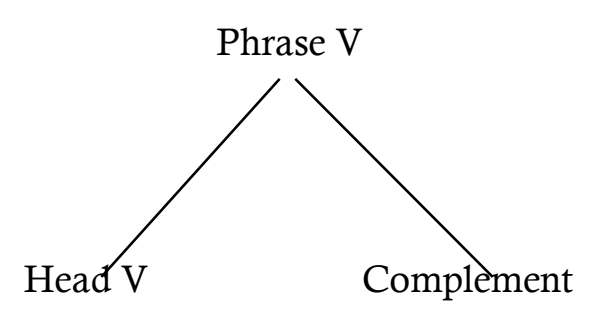

(Adopted from Radford, 2004, p. 67)

The above structure in Figure (1) is understood in the way that the head of the phrase is a verb (v) and merges with an 'internal argument' as a complement to form a verb phrase (Radford, 2004, p. 67).

This study compares and contrasts the parametric variations between the two languages. The noun grammatical structures of the two languages are analyzed and explained according to P\&P theory and Minimalist program (MP) under the concept of Universal Grammar (UG). Since the analysis of the Universal Principles and Parametric variations for the two languages is based on the MP, which requires the representation of the necessary components. The two languages share similarities in terms of definiteness and agreement features under the NP. Crystal (2008) defines NPs as the grammatical constructions into which nouns most commonly enter, and of which they are the head word. The structure of a NPs consists minimally of the noun (or noun substitute, such as a pronoun); the constructions preceding and following the noun are often described under the headings of premodification and postmodification respectively. Similarly, scholars in the field of Kanuri syntax have proposed different definitions to the concept of NP. The NP is a common structural unit, that is usually headed by a noun or another word which can act as a noun in Kanuri (Cyffer, 1991, 1998; Fannami et al, 1999; Bulakarima \& Shettima, 2012; Gazali \& Gombe, 2020; Gazali, 2020). Previous studies on Kanuri NP examine the relationship between the nouns and their modifiers but none of these studies compares the parametric variations between Kanuri and English. Hence this paper examines the parametric variations between Kanuri and English NPs adopting P\&P and Chomsky's MA.

\section{Literature Review}

Cyffer (1991) observes that determiners in Kanuri follow the head nouns. He further opines that when a NP contains additional modifiers, the determiner stands at the end and concludes the NP. Consider the following examples from Cyffer (1991, p. 38) presented in (1a-f) below. 


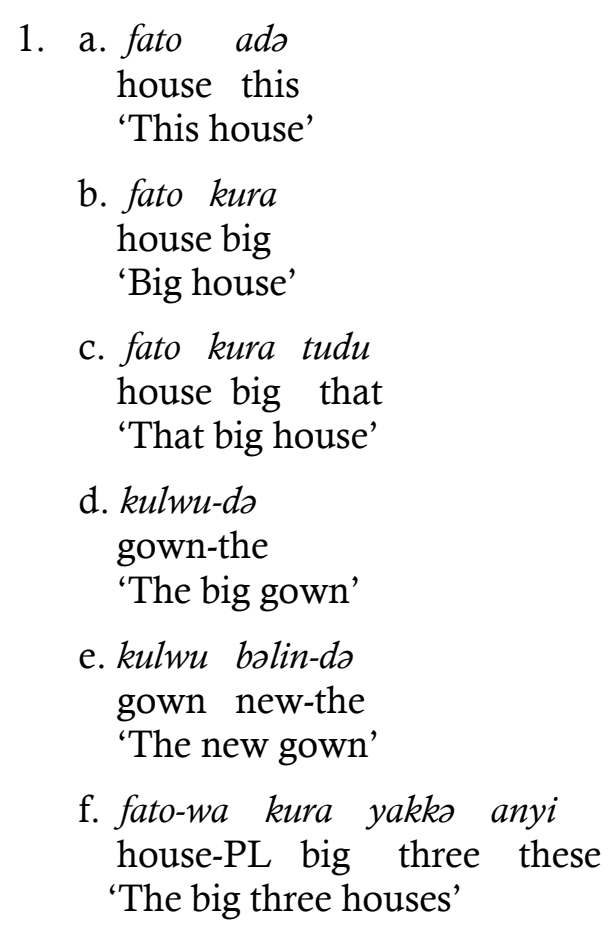

The above examples in (1a-f) show that the determiners and adjectives in Kanuri follow the head nouns and modify them. The definite article 'do' (the), as clitic attaches to whatever word occurring last in the phrase: it can be attached to noun ' $k u l w u$ ' meaning (gown) in Kanuri and in (1d) it attaches to adjective 'bolin' (new) in example (1.e) while in example (1f) it contains complex NP -noun with plural marker '-wa', adjective of size, numerical and determiner which are arranged in linear order. The demonstrative determiner 'anyi' (these) agrees with the head noun in the plural form 'fato-wa' (houses). The Cyffer's study provided us with structural guide on how we compare Kanuri and English NPs.

Fannami et al (1999) argue that Kanuri NPs consist of three slots -pre-head, head and post-head slots. Their analyses observe that the prehead and post-head slots contain optional modifiers/specifiers whereas the head slot contains the obligatory element noun or pronoun. Consider the following examples of the pre-head and post-head slots in (2a, b and 3a, b) adopted from Fannami et al (1999).

$$
\begin{aligned}
& \text { 2. a. ada far } \\
& \text { this horse } \\
& \text { 'This is (a) horse' } \\
& \text { b. ado tada-nyi } \\
& \text { this boy-my } \\
& \text { 'This is my boy' }
\end{aligned}
$$

3. a. tada-nyi

boy-my

'My boy'

b. kel-nyi

trap-my

'My trap'

The above examples ( $2 a$ and $b$ ) are rather sentences than phrases: this is evident by the placement of the modifier 'ado' (this) in the pre-head slot before the head word so the structure becomes a copular sentence. In contrast in examples ( $3 a$ and $b)$ the post-head slot shows a NP consisting of the head word and the post modifier in Kanuri.

Gazali and Gombe (2020) examine the structure of determiner phrases and NPs in Kanuri within the framework of MA and their study identifies Kanuri as post-head initial language -where all determiners and adjectives occur post head in Kanuri. This paper examines the parametric variation of NPs in Kanuri and English - where similarities and differences are examined using the MA.

\section{Methodology}

This section presents the plan of our study. The research design and methodology including research domain, sampling, data collection and data analysis procedures in accordance with the purpose of our study are described in detail.

\subsection{Research Design}

This research is a 'basic' or 'theoretical' -research since the study is based on the implication of the MP in order to analyze the grammatical structure of English and Kanuri languages to set parametric variations between these languages in accordance with the purpose of the study. The study is a comparative through cross-lingual M- design in order to find out parametric variations between the two languages clearly. In this paper, we shall explain the fundamental components of the phrase structures, their descriptions and compare and contrast NPs structures of the two languages - English and Kanuri.

\subsection{Theoretical Framework}

This study does a comparative analysis of Kanuri and English NPs. The study adopts the P\&P framework, and the advancements of the MP to analyze the data collected in the field. The P\&P theory can adequately handle parametric variation between the two languages in terms of differences and their similarities.

\subsubsection{Universal Principle}

By the early 1980s, the 'Extended Standard Theory' which revised the phrase structure rules into Government and Binding (GB) model introduced the concepts of P\&P (Radford, 2009). This section of the paper introduces an outline of the 'P\&P Theory' with their underlying theoretical basis which makes up the core of this paper. 


\subsubsection{Parameters}

The sub-theory such as $\mathrm{x}$-bar, 'movement', move $\alpha, \theta$-criterion, government etc constitute the modules of UG, each of these sub theories is related to different levels of linguistic knowledge such as lexicon, D- structure, $\mathrm{S}$-structure, PF or LF and highlights a universal principle of human languages. Parameters, on the other hand, constitute the modules of UG and each of which determines the cross lingual variations between languages. This means there are Universal principles determining the outlines of the grammar of natural languages and there are also language particular aspects of grammar, varying from one language to another (Radford, 2004). In more concrete terms, if any grammatical operation is observed in a particular human language and not in other, then this operation is regarded as a parametric variation. These particular variations found in the grammars of different natural languages are called 'parametric variation'. To illustrate a parametric variation between Kanuri and English languages, we can give the English NP structure 'The old man' and the Kanuri equivalent NP structure 'Kam caridə' (The old man). English is determiner, adjective and noun NP structure while Kanuri is noun, adjective and determiner structure. Here both languages differ in parametric structure. The parameter setting criteria which this paper adopts is variation between Kanuri and English over the following settings; whether heads (nouns) come first or last (i.e., head initial or head final), whether modifiers arrangements are similar or different. These principles constitute the theoretical basis for the comparative analyses in this paper.

\subsubsection{Minimalist Approach}

The MP refers to a program under the P\&P theory (Chomsky \& Lasnik, 1993). Following the theory's success in solving the logical problem of language acquisition, more methodological criteria giving simplicity and elegance priority become prominent (Boeckx, 2006). In another vein, the purpose of the program is described by the question "granted that the language faculty has a P\&P character, which of the many possible P\&P models is the 'simplest' or the 'most economic' one. What the MP is to answer the question" (Cook \& Newson, 1996, p. 312). Therefore, the program underlines the principle of economy in establishing the necessary elements for UG in which all representations and processes used to drive them are to be as economical as possible.

We adopt MP within this study in the sense of economy in analyzing language particular grammatical features and parametric variations come to the fore. Thus, this study hypothesizes that by getting rid of those superfluous operations in the derivation of grammatical structures, so that the study identifies the parametric variations between Kanuri and English better and easier. The study first identifies what makes the target English grammar distinct from Kanuri one in the Minimalist sense. In other words, the study will find out which underlying minimalist grammatical features and parametric variations lead to differences in the logical forms (LF) of these languages.

\section{Data Presentation and Analysis}

After analyzing the Universal properties of phrase structures which both languages can be described in this paper, we observe language particular properties or features depending on either language (i.e., parametric variations). Raford (2004) remarks thus "if all aspects of the grammar of languages were universal, then all-natural language grammars would be the same and there would be no grammatical learning involved in language acquisition but lexical learning" (p. 81).

\subsection{Head parameter}

- English is a 'head-first' language

- Kanuri is a 'head-last' language

The merging operations and phrase structures in both languages will be as in the following ( $4 \mathrm{a}$ and $\mathrm{b}$ ) in both languages ( $\mathrm{H}$ is for head, $\mathrm{C}$ for complement, and $\mathrm{P}$ for phrase):

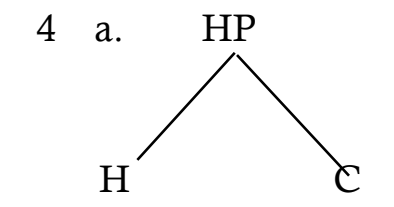

Kanuri Phrase structure

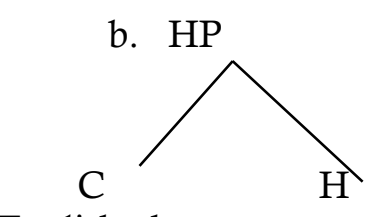

English phrase structure

\subsubsection{Noun Phrases}

Nouns are modified by adjectives, demonstrator (Dem) or qualifiers $(\mathrm{Q})$. In this study, we provide the syntactic properties of NPs in Kanuri and English languages in order to find out their differences and similarities. The following examples in $(5 a, b, c$ and $6 a, b, c)$ which illustrate the nouns specified by modifiers in Kanuri and English below.

4. a. ngərəwu bəlin, ngərəwu dina, ngərəwu sələm

bag new, bag old, bag black

'New bag, old bag, black bag'

b. kakkadəwa ngəwu, kakkadəwa laa, kakkadəwa kalilan

book-Pl many, book-PL some, bookPl few

'Many books, some books, a few books'

c. kakkadəwa anyi, kakkadəwa-də, kakkadəwa tunyi

book-PL these, book-PL-the, book-PL those

'These books, the book, those books'

5. a. new bags, old bags, black bags

b. many books, old books, a few books

c. these girls, the house, that man

The above examples (5a, b, c and $6 a, b, c)$ are headedness principle. These words are not the complements of each other and are heads of the phrases ('ngərəwu' (bag), 'kakkkdə' (book), bags, books and girls) are nouns modified by their demonstratives and adjectives in Kanuri and English. The variation shows that modifiers, quantifiers and adjectives come after the head nouns in Kanuri while modifiers, quantifiers and adjectives come before the nouns in English. The modifiers, quantifier and adjective (new, many, these) are specifier which serve to extend a lexical item or a phrase into a larger expression. Consider the following examples of merge operation of the minimalist structure in $(7 \mathrm{a}$ and $\mathrm{b})$ below. 

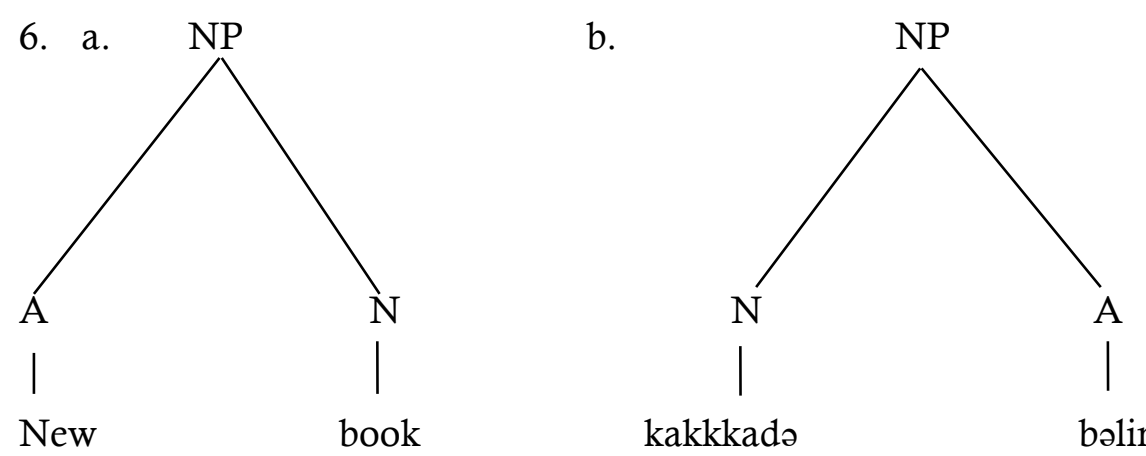

The above examples ( $7 \mathrm{a}$ and $\mathrm{b}$ ) show the words 'bolin' and 'new' are adjectives in English and Kanuri which are merged and resulted into a NP 'new book'. The analysis shows that the adjective 'new' precedes the noun 'book' in English while the adjective 'bolin' (new) occurs post head-head position in Kanuri.

\subsubsection{The Headedness Principle}

Nouns are the complements of other lexical or functional categories. The concept of NP is under operation when nouns are modified by adjectives, demonstrators (Dem) or quantifiers. The heads of the phrases are still nouns modified by an adjective, a quantifier or a demonstrator. The modifier is a 'specifier' which serves to extend a lexical item or a phrase into a larger expression. The structures in (8a, $b$ and $9 a, b$ ) below illustrate the headedness principle of specifier (modifier) with head nouns in Kanuri and English.
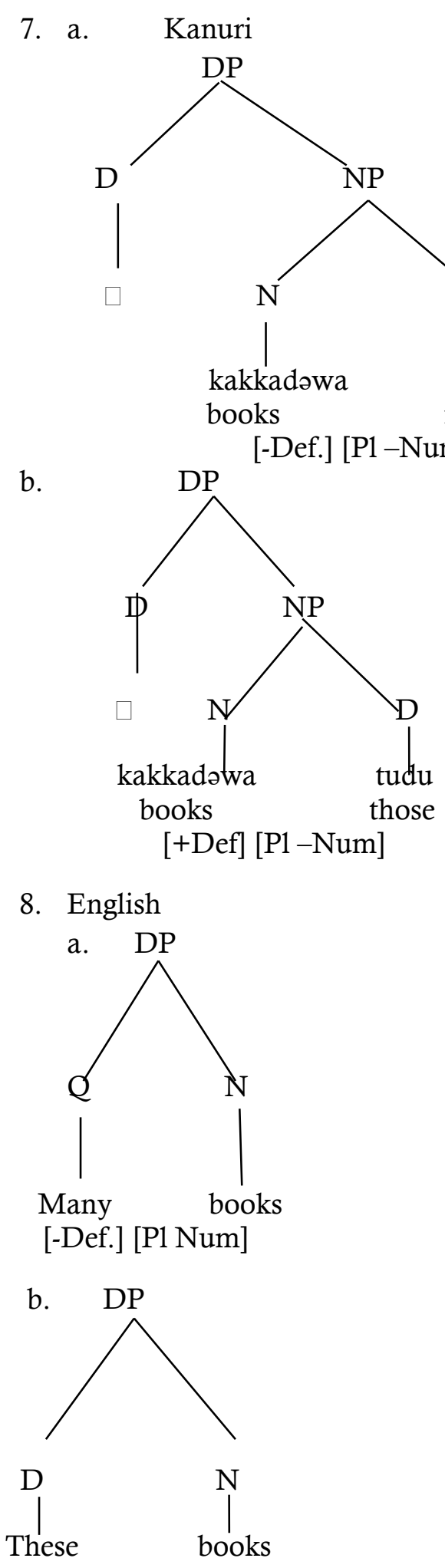

[+Def.] [P1 Num]

The above examples in $(8 \mathrm{a}, \mathrm{b}$ and $9 \mathrm{a}, \mathrm{b})$ illustrate the headedness principles of the quantifiers and determiners in Kanuri and English noun phrases (DP). The two languages have different parametric variations to the head parameter but show similarities to the headedness principal agreement. Quantifiers do not show definiteness to their head words while the demonstrative determiners in both languages show definiteness to their head noun [+Def.]

\subsubsection{Possessives, Quantifiers, adjectives and Nouns in Kanuri and English}

Another grammatical structure function under the NP in Kanuri and English is possessives and quantifier plus the head nouns. Comparatively, these three elements are arranged in linear order according to different language structure. This can be illustrated in example (10 a, b, c and 11a, b, c) below.

Kanuri and English structures

9. a. Sawa-wa-nzə samma 
friend-PL-his all

N-PL-Poss Q

N-PL-Poss Q

'All his friends'

b. am-nde samma

people-our all

N-Poss

N-Poss Q

'All of our people'

c. fero-wa sənana inditudu girl-PL small two those girl-PL adjective two those

'Those two small girls'

10. a. All his friends

Q Poss Noun-PL

'All his friends'

b. All our people

Q Poss N

'All our people'

c. Those two small girls

Dem Num. Adj N-s

'Those two small girls'

The above examples in $(10, b, c$ and $11 a, b, c)$ show possessive, quantifier, demonstrative, adjective and noun orderings comparatively between the two languages. The above examples in (10a, $b$ and $c)$ show quantifiers, possessives and adjectives occupy the rightward position of the nouns in Kanuri while in examples (11a, b and c) the same modifiers -determiners, quantifiers and adjectives occupy the leftward position in English. The above examples further show that there are similarities in plural formation in both languages -the plural formation in the two languages is morphological realized and they occupy the rightward position. This can be structurally presented in tree diagram below.

11. Tree structure of Kanuri Noun Phrase (DP)

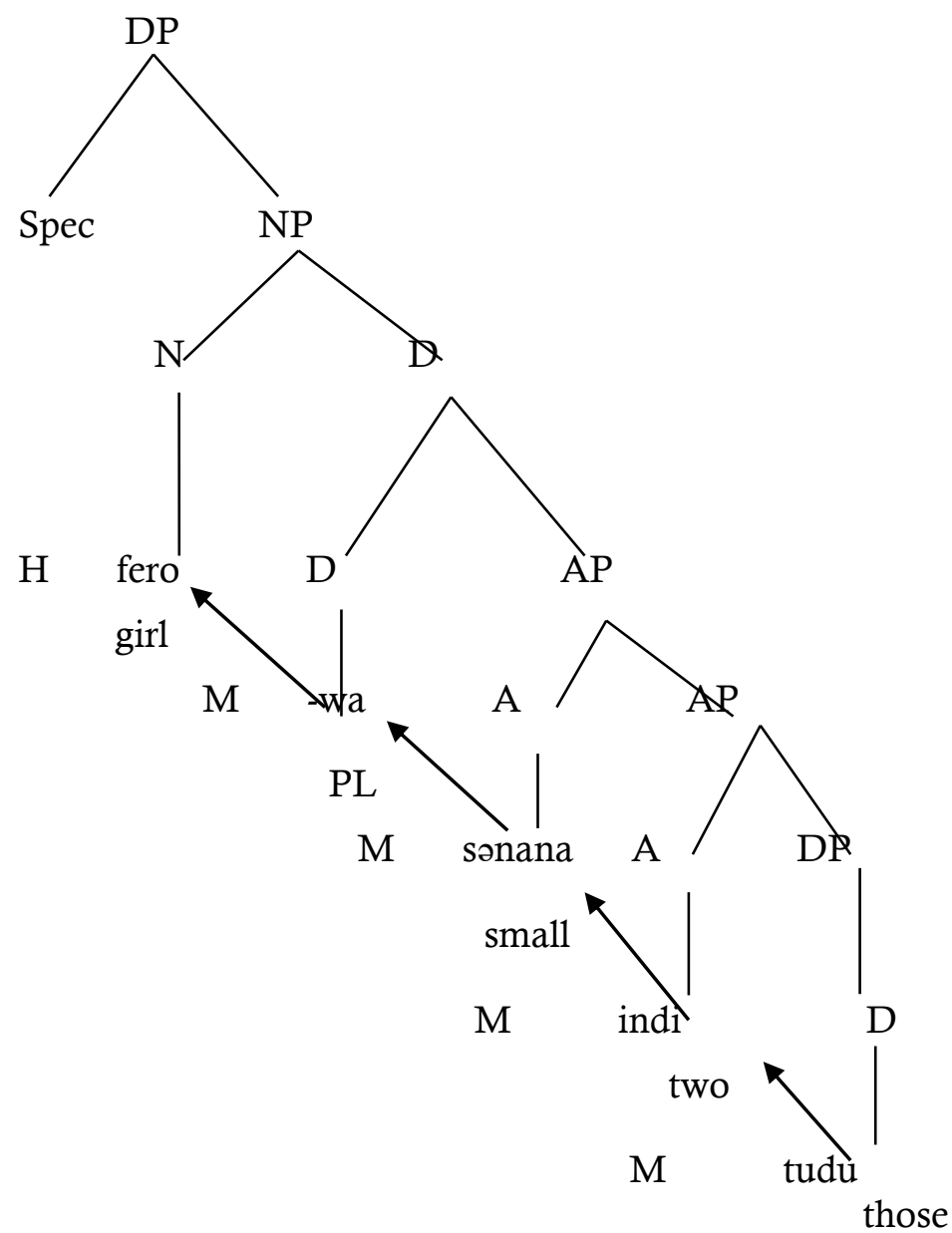

The above structure in (12) shows syntactically linear arrangement of Kanuri NP structure using the MA framework. The NP is a projection of determiner phrase (DP). The DP is further projected into specifier and complement position. The NP in further projected into specifier noun with complement arranged in linear order - plural marker-wa morphologically suffixed to the noun 'fero' (girl), adjective of size 'sənana' (small), adjective of number 'indi' (two) and demonstrative determiner 'tudu' (those). The noun 'fero' (fero) occupies the rightward position. 
12. Tree structure of English noun phrase

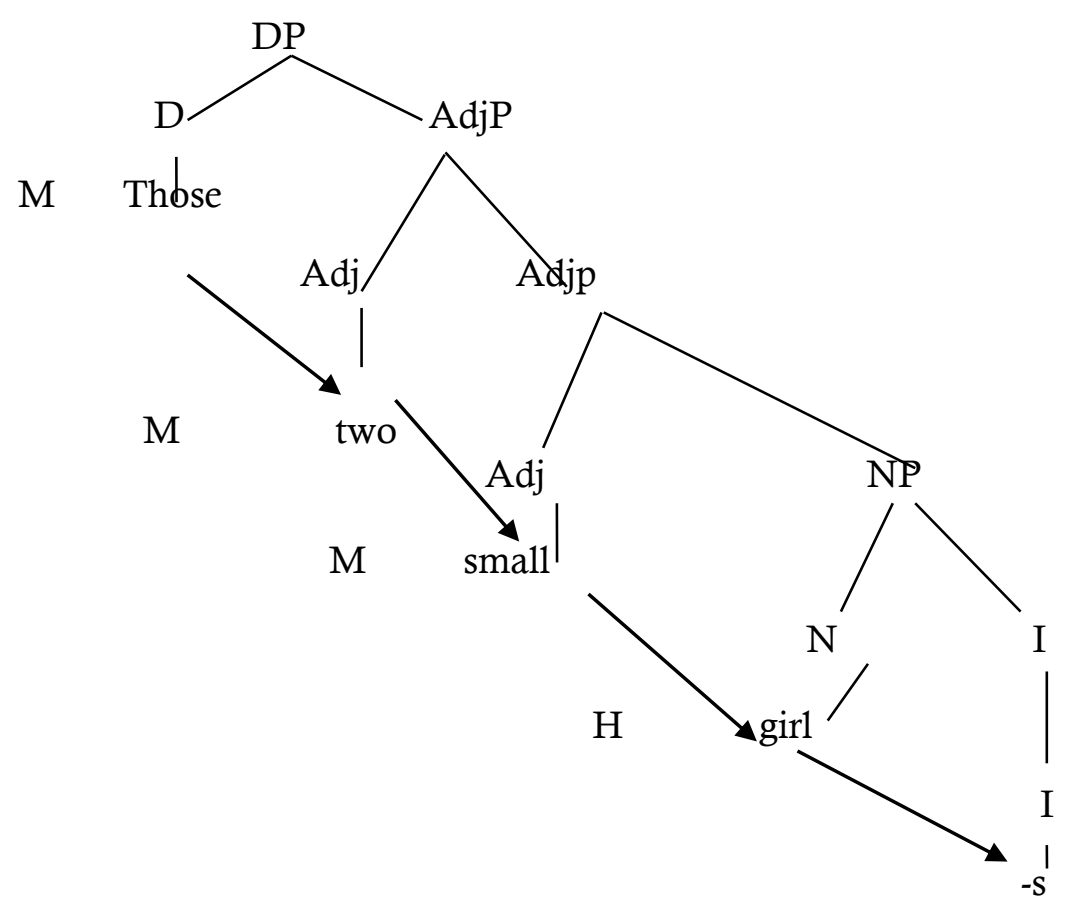

The above structure in (13) shows structural pattern of English NP (DP) structure. The DP is the projection of determiner (D) as specifier of the head noun (girl) which has same interpretable feature [+plural] [+Agr]. The complements as modifier of the noun $(\mathrm{H})$ specifier are determiner (D) 'those', adjective of numerical 'two' and the adjective of size 'small' modifying the head noun 'girls'. The modifiers are arranged in linear order but the plural inflectional $-\mathrm{s}$ is morphologically suffixed to the noun which is similar to Kanuri language.

\section{Conclusion}

The study analyzes the parametric variations of Kanuri and English NPs within the framework of P\&P theory adopted the Chomsky's MP. The study identifies the differences and similarities between the two languages. The two languages NPs share different syntactic arrangements. Kanuri is head last language while English is head initial language. In terms of head specifier and complement position, complements come after the head noun in Kanuri while complements come before the head nouns in English. The two languages differ in the arrangement of the modifier types. Kanuri language allows the pattern adjective of size, numerical adjective and determiner order while English pattern of arrangement is determiner, numerical adjective, adjective of size, adjective of colour arrangement before the head noun. On the relationship between the head and their complements, complements occupy leftward position in English while complements occupy rightward position in Kanuri. Finally, the study observed similarities between the two languages although they are genetically different languages both languages suffix their plural markers morphologically after the head nouns and similarities in marking definiteness and agreement features.

\section{References}

Boeckx, C. (2006). Linguistic minimalism: Origins, concepts, methods, and aims. Oxford University Press.

Bulakarima, S. U., \& Shettima, A. K. (2012). A Sketch of Kanuri phonology and Tone. Desktop publishers cooperative society, Maiduguri.

Cook, V. J., \& Newson, M. (1996). Chomsky's Universal grammar: An Introduction. Blackwell, Oxford.

Chomsky, N., \& Lasnik, H. (1993). 'Principles and Parameters Theory', In Syntax: An Introduction Handbook of Contemporary Research, de Gruyter, Berlin.

Chomsky, N. (1995). The Minimalist Program. Cambridge, Massachusetts: The MIT Press.

Crystal, D. (2008). Dictionary of Linguistics and Phonetics. Sixth edition. Blackwell, UK

Cyffer, N. (1991). We Learn Kanuri. Koln, Rudiger Koppe Verlag.

Cyffer, N. (1998). A Sketch of Kanuri. Koln, Rudiger Koppe Verlag.

Fannami, M., Munkaila, M., \& Bulakarima, S. U. (1999). 'The Structure of Kanuri noun phrase' In Attah et al (eds.) A Book of reading faculty of Arts, University of Maiduguri Occasional publication, Maiduguri.

Gazali, B. K. A., \& Gombe, M. U. (2020). 'The Structure of noun phrase and determiner phrase: Minimalist approach' in Linda (ed.) Journal of Linguistics, language and culture. Nnamdi Azikwe University Awka, Nigeria.

Gazali, B. K. A. (2020). 'Kanuri DP Hypothesis' In Sastra, G. (ed.) Jurnal Arbitrer. Faculty of Humanities, University Andalas, Indonesia.

Radford, A. (2004). Minimalist Syntax: Exploring the Structure of English. Cambridge University press, Cambridge.

Radford, A. (2009). Analyzing English Sentences: A Minimalist approach. Cambridge University Press, Cambridge.

Trask, R. (1993). A Dictionary of grammatical Terms in Linguistics. Routledge, Cornwall. 